\title{
A DISCOURSE DESCRIPTION OF FOUR FUND- RAISING TEXTS - LINGUISTS MEET PRACTITIONERS: AN EXPLORATORY STUDY
}

\author{
Patrick Chi-Wai Lee
}

\begin{abstract}
This exploratory study presents four fund-raising texts for an analysis. Two are written as appeal letters and two as leaflets. Their purpose of writing is to persuade an audience of Hong Kong residents to donate money for charity organizations. A qualitative approach informed by ethnography is adopted. Interviews with two organizations are conducted and verbal reporting of practitioners is used. In this study, one focus is on the schematic structure of texts and fund-raising texts are recognized as a particular of genre. The 'Problem-solution discourse pattern' can be applied to the fund-raising texts even though practitioners did not acknowledge they use any linguistic models. As for the textual moves, 'situation or problem' is always placed at the beginning of the text because it is crucial to let readers know what the main theme is. Then there are different combinations of the second move including 'response, solution or problem'. The final move is always 'response' and two meanings of 'response' are refined to different parameters: (i) tangibility: tangible and virtual solution, (ii) time frame: proposed and reference solution, and (iii) depth of target-achievement: ultimate and specific solution. Another focus of this study is on the choice of style. As persuasion of readers to donate is crucial, adding involving devices is to engage readers and make them 'particular', which increases the possibility to solicit response successfully. Involvement devices include using you and imperative clauses. Finally, with reference to the issue of whether 'textual structure tells us the reality' or 'the reality creates the structure', practitioners are not concerned too much with text structure. Practically, the reality to them is embodied in the structure.
\end{abstract}

\section{Keywords}

choice of style, ethnography, fundraising, text-structure, practitioners

\section{Introduction}

This exploratory study presents four fund-raising texts for an analysis: two are written as appeal letters, and two as leaflets. Their purpose of writing is to promote the cause of charity, that is, to persuade an audience of Hong Kong residents to donate money for earthquake victims, for the education of children, and the organizations: (i) Oxfam Hong Kong and (ii) United Nations International Children's Emergency Fund (UNICEF) Hong Kong. The choice of these texts is motivated by an interest in this type of writing which does not promote goods or services, but charity. The audience is not asked to purchase a commodity but 
to give away money for something which they cannot redeem personally. The question arises how this type of writing can be viewed in line with other types of promotional writing, especially, whether there is some particular genre after which the fund-raising texts are modelled. The question of 'genre' begs another question in the context of this study. If a 'genre' patterns a text, where does the pattern come from? Does it reside in the authors' mind as some conventionalized knowledge? What is the structure of fund-raising texts and how do practitioners write a fund-raising text that can persuade readers to donate? How do the linguists and the practitioners inform one another on writing fund-raising texts? In this study, there are three aspects of investigation; they are: (i) text-structure analysis, (ii) choice of style, and (iii) practitioners' voices. Two mixed research methods of ethnographic interviews and text-structure analysis were adopted for achieving those three goals of this study.

\section{Background}

\subsection{Fund-raising text and promotional writing}

The prime example of promotional writing is also advertising. Among many others, Rotzoll et al. (1986), Kotler and Armstrong (2014), and Wharton (2015) discuss the basic functions of advertising and identify two primary roles: to inform and to persuade, and an effective advertising links the wants and needs of the consumer with the properties and functions of the product. According to Weinstein (2009), fund-raising texts share with these diverse advertisements this one feature, i.e. the persuasive function. They persuade readers to donate for charity. More specifically, Clarke and Norton (1997: 21) state that "a fundraising text is more about 'selling' than 'telling' and it is about persuading people to give". In previous studies, different linguists have used different approaches for conducting an analysis of the same fund-raising letter. Let me cite as an example and a case in point the twelve contributions in Mann and Thompson (1992). Twelve papers contributed by linguists used different approaches to analyze one and the same fund-raising letter. The differences in approach resulted from different degrees of detailing of clause relations, and of degrees of focus on either genre or register. The authors tried to do justice to a "diversity of language functions" (Mann \& Thompson 1992: 2). For instance, Callow and Callow (1992) assume that text structure follows from intended meanings, and they also suggest 'coherence relations' to hold between units of the text; Mann et al. (1992) propose the Rhetorical Structure Theory which views the entire text in terms of the relations among its component parts, and the same relations are assumed to hold at all levels of text-structure. In addition, Winter (1992) addresses the 
issue of textual organization in terms of answer-and-question approach. It is concluded that from seeing different analyses at work for one and the same text, it is clear that "there is no consensus on what the relevant set of function is" (Mann \& Thompson 1992: 1). It should be also noted that there were numerous research studies related to genre analysis and philanthropic fundraising texts (cf. Bazerman 1997, Bhatia 1998, 2004, 2010, Connor \& Gladkov 2004, among many others). ${ }^{1}$ Particularly, Bhatia (1998) suggests that philanthropic fundraising texts also have similar text-structures as those in promotional letters in business contexts. Bhatia (2004: 95) further states that "philanthropic fundraising genres and commercial advertising genres can be grouped together in the same broad category of promotional discourse", and also proposes a seven-move structure in a fund-raising text; they are: (1) establishing credentials, (2) introducing the offer, (3) offering incentives, (4) enclosing documents, (5) soliciting response, (6) using pressure tactics, and (7) ending politely.

Among different approaches of analyzing a fund-raising text, I select the Problem-Solution Structure approach most prominently advocated by Winter (1976) and Hoey $(1983,1991,2001)$ for my own analysis in this study. It is because during ethnographic interviews with the two fund-raising organizations practitioners point to a sequencing of textual components which is equal or similar to the Problem-Solution Structure advocated by Winter (1976) and Hoey (1983, 1991, 2001) (cf. Section 4.3.1). Hence, I will emphasize the question of relation of reality and text structure, a question which is mentioned as some kind of sideplay in their work only, but should be put forward very clearly so as to create more and more awareness of textual properties. More specifically, Hoey $(1991,2001)$ explains that the projection of written monologue into questionand-answer dialogue form is an important test of the structure of a discourse. He further points out that it might be argued that the possibility of such projection is the consequence of describing not the language but the reality which the language encodes. The linguistically encoded problems and solutions, however, need not be seen as real world problems by a reader, nor need the reader accept a linguistic solution as a real-world solution. How then does the reader identify the writer's problem and solution? Presumably it is because they have been presented as such in the language itself. But what exactly are the techniques or devices used for encoding real world problems and solutions in language? For investigating those questions, the viewpoints of Winter (1976) and Hoey (1983, 1991, 2001), and practitioners on textual properties and the reality of problems and solutions will be studied in Sections 2.2 and 4.3. 


\subsection{The schematic structure of discourse: Problem-Solution Structure (Winter, Hoey)}

There have been many attempts to label and classify the conventional patterns of discourse, to specify the kinds of order that people provide in their communications. Today many still find the organizational patterns described by Grimes (1975) useful for describing many texts. The following patterns are three sets of discourse patterns adapted from Grimes (Spivey 1997: 72-75): (i) collection, (ii) causal and (iii) chronology. First, a collection is seen as a loose kind of rhetorical relation, which might 'hold together' various kinds of content. For instance, a topically focused report would present a discussion of the various aspects of one subtopic, then aspects of another and another, and so on. Second, a causal pattern might have effect first or cause first, but 'effect followed by cause' is the order often used for causal arguments or other large pieces of written discourse. Third, chronology is a separate pattern because of the temporal relation that characterizes it. Other patterns can be response. Response, according to Grimes (1975), has some content from a first part that is repeated in a second part along with new material. Response can have within it units that relate to each other as problem-solution or question-answer.

It was Winter (1976) and Hoey (1983, 1991, 1994, 2001) who started to label the organizational structure of texts as the Problem-Solution discourse pattern to be applied to discourse as disparate as fairytales and interviews. One significant difference between their works and earlier studies is that they have tried to explore the means of identifying the pattern instead of merely naming the various structural categories. Hoey (1994) further explains how a simple constructed example can be expanded in a question-answer format. The example (constructed by Winter) is as follows (Hoey 1994: 28):

SituationI was on sentry duty.

ProblemI saw the enemy approaching.

ResponseI opened fire.

EvaluationI beat off the enemy attack.

Below, the projection into a question-answer dialogue, which allows hearers and readers to infer the function of the textual moves, is provided (Hoey 1994: 30):

\footnotetext{
A: What was the situation?

$B: I$ was on sentry duty.

A: What was the problem?
} 


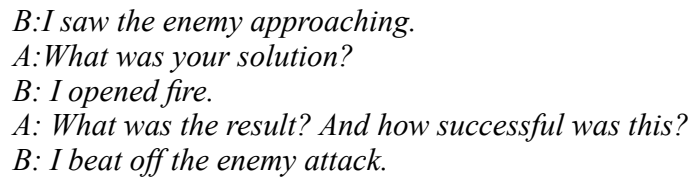

The textual moves are not only inferable by way of reference to the pragmatic knowledge of expectations towards the nature of the next question. Textual moves are also discernible by 'lexical signals'. Lexical signals are not in a oneto-one relationship of linguistic categories and textual step. They can be roughly summarized as follows:

Situation

Problem

Solution/Evaluation lexically signalled by noun expressions and mostly present tense

lexically signalled by various linguistic devices which readers identify as requiring a response

lexically signalled by noun expressing quantity and/or successful closure of a course of action, by evaluative adjectives and adverbs, by verbs aspect expressing achievement

Hoey $(1994,2001)$ reports that some of the earlier linguists had worked on similar discourse structure. In narrative discourse, similar components have featured in some of the structures studied, among others, in Labov (1997) and Van Dijk (1993, 2001). Van Dijk notes the existence of the structure 'settingcomplication-resolution-evaluation-moral' (as quoted in Hoey 1994: 27). At the same time, Van Dijk recognizes that for scientific discourse, the structure is often of the form 'introduction-problem-resolution-conclusion'. To conclude, it should be clear by now that the 'Problem-Solution Structure' is one of the major descriptions of genres.

\subsubsection{Sub-genres: Direct mail (appeal letter and leaflet)}

Bhatia $(1993,2008,2010)$ points out that the shared set of communicative functions shapes the genre and this gives it an internal structure. Fundamental changes in the communicative purpose(s) are likely to give us another kind of genre. Instead, slight modifications or minor changes would help us distinguish sub-genres. In our daily life, practitioners of non-profit making organizations will send printed matters to the donors by direct mail regularly. Also, appeal letters and leaflets are categorized as sub-genres which have the common way of the delivery mode - direct mail, and those two sub-genres are the subjects to be 
studied within the scope of study in this research (cf. Table 1 for differences and similarities between those two sub-genres).

\begin{tabular}{|c|c|c|}
\hline Sub-genres & Appeal letter & Leaflet \\
\hline \multicolumn{3}{|c|}{ DIFFERENCE } \\
\hline Format & $\begin{array}{l}\text { Letter } \\
\text { (With salutation and complimentary } \\
\text { closing) }\end{array}$ & $\begin{array}{l}\text { Text } \\
\text { (Passage-format) }\end{array}$ \\
\hline Frequency & $\begin{array}{l}\text { Regularly } \\
\text { (around 4-5 times per year) }\end{array}$ & $\begin{array}{l}\text { For specific incidents } \\
\text { (e.g. earthquake) }\end{array}$ \\
\hline Delivery mode & Direct mail only & $\begin{array}{l}\text { Direct mail and/or promotional } \\
\text { activity }\end{array}$ \\
\hline \multicolumn{3}{|c|}{ SIMILARLITY } \\
\hline Function & \multicolumn{2}{|c|}{ Producing desire for readers to contribute } \\
\hline Topic & \multicolumn{2}{|c|}{ A main theme: Children's Education, Women's Rights, etc. } \\
\hline
\end{tabular}

Table 1: Differences and similarities between two sub-genres

\subsection{Choice of style: Involvement in discourse}

Some literature about the schematic structure has been reviewed above. Another focus of this study is the choice of style - reader involvement. For fundraising letters, involvement devices are used, such as the personal pronoun you and imperative clauses. When discussing involvement, among others, Tannen $(1989,2005)$ points out that involving in conversation means making particular. More specifically, Tannen (1989: 9) comments that "the particular event is also represented as a scene in which the described characters, objects, and action figure, and their ideas and feelings associated with such a scene are thereby triggered". Fund-raising texts are written ones and the different involvement devices are used to be associated with particularity and therefore create involvement. Tannen also states that those involvement devices elaborated in literary discourse can create interpersonal involvement. The purpose of including considerations of involvement style is to get some hold of, that is, some better understanding of the persuasive function of promotional writing. The request to donate money targets a reader who does not need to budge. Donations are normally made on an entirely voluntary basis. Donations cannot be effected by laws. Since the request for making a contribution to charity is addressing readers as volunteers, 
they have to be addressed as equals, as fellow human beings of the victims of catastrophes and of the writers of the fund-raising texts.

To conclude, the choice of style is studied with reference to the notion of reader involvement. For fund-raising texts, the use of the word you and of the imperative clause are perceived as involvement devices, and in this study it is assumed that they serve to make readers equal. Another way of saying this is to assume that by the use of these devices readers are made to feel to cohere with created scenes and the writers' intentions. They therefore become volunteers and can be persuaded to some action.

\section{Methodology}

This section is structured as follows. It will first be outlined what the three research goals are, and then explained why altogether four texts, two fund-raising letters and two leaflets, have been chosen. The rationale for consulting with practitioners from two charity organizations (UNICEF and Oxfam) will then be explained. This section is concluded by an elaboration of 'Problem-Solution Structure', whose basic structure has been introduced earlier. For understanding how the analysis in Section 4 proceeds, it is necessary to present also some of the variations which the steps in the above structure may undergo.

\subsection{Research goals}

Fund-raising texts from non-profit making organizations may share the same persuasive purpose with advertisements, but there is no 'physical product' or 'service' offered in the text. It is worth noting that how the practitioners write a fund-raising text can persuade readers to donate. Hence, this study is designed with the following three goals:

1) To examine the schematic structure of fund-raising texts written by the practitioners;

2) To study the choice of style of fund-raising texts written by the practitioners;

3) To explore how the linguists and the practitioners inform one another on writing fund-raising texts.

\subsection{The collection of the texts under study}

More than fifty texts were collected and four texts were finally chosen for this study. Those four texts, which are taken from two international non-profit making organizations in Hong Kong, are regarded as standardized and they appear to be most representative, as quoted from the interviewed practitioners in this study. 


\subsection{Research design: Ethnography}

Language cannot be studied in isolation and should be examined within cultural and social settings. Analyses, models or rhetorical structures are built and organized from and in language. For any theoretical undertaking is valid what is valid for all other kinds of meaning making: those engaged in the process of that social practice which is the focus of the observer's work should be included with their views and opinions regarding the relevant properties of their work. For this research, a qualitative approach of ethnography is used. Among others, Atkinson (2001), Atkinson and Hammersley (2007), Bryman (2008), Kaplan-Weinger and Ullman (2015) explain that ethnography involves genuinely social interactions in the field with participants of the study. Specifically, Atkinson and Hammersley (2007: 1) explicitly state that "in its most characteristic form it involves the ethnographer participating ... watching what happens, listening to what is said, asking questions - in fact, collecting whatever data are available to throw light on the issues that are the focus of the research".

\subsubsection{The ethnographic interview}

With reference to the research goals, the aim is to study the structure and the choice of style of a fund-raising text written by the practitioner and how the linguists and the practitioners can inform one another on writing those texts. Hence, social interaction with non-profit making organization is made by conducting interviews - asking the practitioners questions, listening to what is said. Bhatia $(1993,2004,2008,2010)$ concludes that a good genre analyst attempts to examine the organizational situation, in which the genre and the rules that command the use of language are used in such organizational settings. Bhatia (1993: 24) further states that "these rules and conventions are most often implicitly understood and unconsciously followed by the participants in that communicative situation in which the genre in question is used - or explicitly enforced in some organizational settings". For this research study, organizational visits with ethnographic interviews were conducted by the author of this paper, primarily aiming to ask practitioners to elaborate and explain, to reflect on the writing process of fund-raising texts, and also to describe how they feel about it. Secondly, the visit also aims to collect organizational documentary materials, including other fund-raising texts and newsletters.

As for the ethnographic interviews, those two organizations arranged a representative as an interviewee. I should acknowledge that though the interviewee from each organization was not the writer of my target sample texts ${ }^{2}$, the interviewees are, however, the ones who write other fund-raising texts, or 
who have a role in the writing process for the organizations. It should also be noted that the interviewees admitted that they can clearly answer questions about their fund-raising texts, and they were from:

1. Fund-raising Section of a Hong Kong Committee For UNICEF

2. Policy and Public Education Section of an Oxfam Hong Kong

\subsubsection{Text-maker's own typology of the genre within the fund-raising text genre (ethnographic assumption)}

In order to probe relevant data from interviewees for achieving the objective of how to write a fund-raising text practically, a list of questions was made and it was a guideline for making the organizational interviews. The interviews were guided by the open-ended questions which are adapted from Gunnarson (1997) and they are sub-divided into seven areas:

\begin{tabular}{|c|c|}
\hline AREAS & QUESTIONS FOR AN INTERVIEW \\
\hline 1. Types of texts & - What types of texts do you write at your workplace? \\
\hline 2. Reasons for writing & - Who asks you to write the texts? \\
\hline 3. Writing process & $\begin{array}{l}\text { - Who checks the texts? } \\
\text { - Who signs the texts? } \\
\text { - How would you describe your writing procedure? }\end{array}$ \\
\hline 4. Readers of texts & - How well do you know the reader(s) of your texts? \\
\hline $\begin{array}{l}\text { 5. Criteria of assessing } \\
\text { the texts }\end{array}$ & $\begin{array}{l}\text { What is/are the most important criteria in evaluating } \\
\text { the effectiveness of a text? }\end{array}$ \\
\hline 6. Forms and model texts & $\begin{array}{l}\text { - Does your organization use the same forms since you began } \\
\text { working in it? } \\
\text { - Have you had any chances to change the forms? }\end{array}$ \\
\hline $\begin{array}{l}\text { 7. Individual attitude } \\
\text { towards writing }\end{array}$ & $\begin{array}{l}\text { Which of the text types do you think is particularly } \\
\text { challenging for you to produce? Why? }\end{array}$ \\
\hline
\end{tabular}

Table 2: Guided questions for interviews

Moreover, an approach of a verbal reporting is used for gathering data about the process the practitioners in the non-profit making organizations employ in writing a fund-raising text. Richards, Platt and Platt (1998: 498-499) explain that "verbal reporting involves the practitioners giving oral description of the process they are using and it attempts to gather information about the cognitive and linguistic aspects involved in different kinds of tasks". 


\subsection{Unit of analysis: Problem-Solution Structure}

The reasons for choosing four texts and conducting ethnographic interviews in this study have been mentioned above. Then, the unit of analysis for this study is the basic category labels of 'Problem-Solution Structure: situation, problem, response, solution and evaluation'. In addition, the following section is to present the basic and also some variations of the category labels in 'ProblemSolution Structure'. The framework of the 'Problem-Solution Structure' has been elaborated in Section 2.2. above. At this point, further refinements of the structure will be presented which will be adopted for the analysis in Section 4.1.

Further to the basic category labels, there are some variations of 'ProblemSolution Structure' to be noted. Hoey $(1994,2001)$ obviously recognizes some of the complexities involved in analyzing the 'Problem-Solution Structure'. He further concludes that what began as an apparently straightforward examination of related patterns (problem-solution and hypothetical-real) of organization has ended in muddy water. He also suggests that such patterns are not as distinct as they seem and the patterns are interactive. In addition, people generally expect a positive evaluation of the response. This will give a feeling of completeness and thus will round off the text. In this case, the response component can also be called solution component. But there may be stages where solutions are rejected or partially accepted. This is where negative evaluation comes into place. Negative evaluation implies that another problem arises and this will produce another cycle of the problem-solution pattern, as illustrated below:

Situation
Problem
Response (attempted solution)
Evaluation (negative) =

Problem

Response (attempted solution) Evaluation (negative) $=$ Problem, etc.

One may see that negative evaluation may generate recurrent response. Strictly speaking, the use of solution may imply a successful response.

The above are elaboration of basic and some variation on category labels of 'Problem-Solution Structure'. The basic category labels are the units of analysis for Section 4.1 in this study, and there may be some refinement on those labels when the analysis goes on. On the other hand, the format of analysis is presented with reference to segmentation within the text and finally, the function of each segment is explained. 


\subsection{Format of analysis: Segmentation within text, function and explanation}

Each sample text is divided into single units, i.e. segments (Seg.), and the segmentation is intended to be a superficial, simple reflection of visible subdivisions (most often sentences, but not always). With reference to the textstructure analysis of all those segments, this study is to analyze how the words and syntactic structure create effects as the text is read. The function of each segment is reviewed and the rhetorical purpose of each segment in the text is explained. Segments, functions and explanations are related in columns. How different types of segments are treated is exemplified below (Seg. 1-2)

Seg. 1

Text Dear Reader,

Function: Salutation

Explanation: Crucial to the reality of a letter, personal touch with the reader

Seg. 2

Text Alittle help from our donors has repaired 380 school buildings this year

Function: Solution (referent solution; previous record)

Explanation: Referent solution (carried out in the past) is quoted as an evidence of showing readers the use of resource.

\section{Findings and analysis}

As stated earlier, the focus of this analysis is on two appeal letters and two leaflets from two non-profit making organizations in Hong Kong: (i) UNICEF and (ii) Oxfam. The representatives of these two organizations were also interviewed. In addition, the focus of the analysis is on the schematic structure and on the choice of style in the text.

\subsection{Schematic structure}

\subsubsection{Application of Hoey's category labels to data text}

Referring to Hoey (1994, 2001), the fuller name for the 'Problem-Solution Structure' is situation-problem-response-solution-evaluation discourse structure. The steps of 'Problem-Solution Structure' are defined by elaboration of the details of the textual sequences in this study. 'Situation' is defined as a state at a particular time, set of conditions, facts and events having an effect on a person, society, etc. 'Problem' is defined as an aspect of the situation required as a response. In addition, response for fund-raising texts is refined as (i) an action of donating money from readers and (ii) a reply to the problem by the charity organization. Solution is defined as contains within it an evaluation of a 
particular response as successful. Finally, 'evaluation of solution' is defined as an appreciation or a desired result of solution. In addition, lexical signals are not in a one-to-one relationship of linguistic categories and textual steps. They can roughly be summarized as: 'situation' is lexically signalled by noun expressions and mostly present tense; 'problem' is lexically signalled by various linguistic devices which readers identify as requiring a response; 'solution/evaluation' is lexically signalled by nouns expressing quantity and/or successful closure of a course of action, by evaluative adjectives and adverbs, by verb aspect expressing achievement. In summary, Table 3 is to list out the basic and refined category labels which can be applied to the data texts.

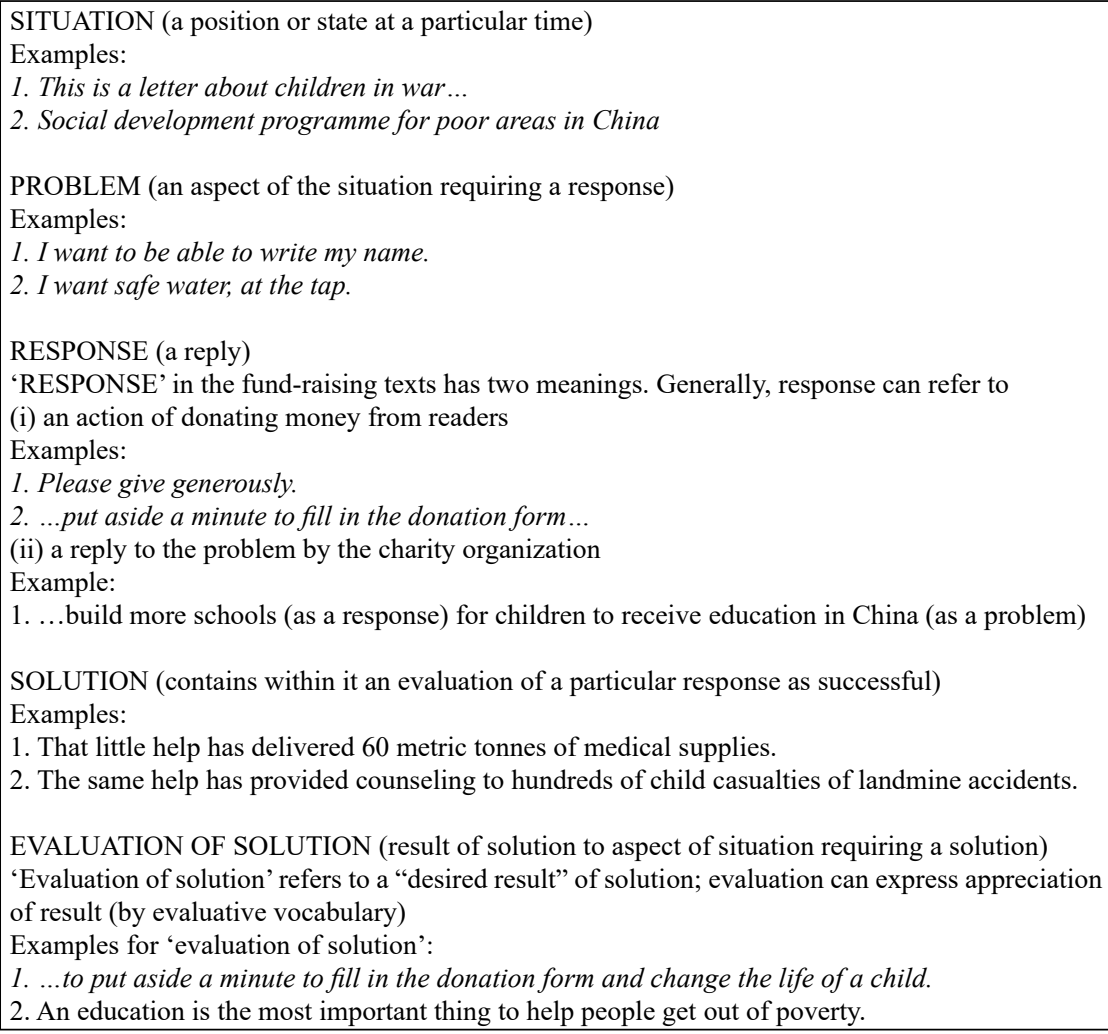

Table 3: Steps in 'Problem-Solution Structure' for fund-raising texts 


\subsubsection{Explanation of illustrated analysis in table form}

As stated in the methodology section above, four data texts are analyzed in respect to each segment and its function. The function of each segment is explained with examples and Table 4 below is an illustrated analysis (Segments 1 to 13) of data text 1, i.e. Appeal letter from UNICEF. The data text 2 is an appeal letter from Oxfam; the data texts 3 and 4 are leaflets from UNICEF and Oxfam.

One major finding of these analyses is that the steps of 'response' and 'solution' should be in a finer sub-categorization than is allowed by general labels. In this section, the finer sub-categorizations are not yet labelled. The differences are accounted for mainly in the column explanation.

\begin{tabular}{|c|c|c|c|}
\hline Segment & TEXT & FUNCTION & EXPLANATION \\
\hline Seg. 1 & Month, Year & Date & $\begin{array}{l}\text { Date is crucial to the reality of } \\
\text { the letter. }\end{array}$ \\
\hline Seg. 2 & Dear Reader, & Salutation & $\begin{array}{l}\text { Crucial to the reality of a letter } \\
\text { Personal touch with the reader }\end{array}$ \\
\hline Seg. 3 & $\begin{array}{l}\text { Can you stop reading and } \\
\text { think about something else? }\end{array}$ & Relational Opening & $\begin{array}{l}\text { Relational open (between Dear } \\
\text { Reader and you in Seg. } 2 \text { and 3) }\end{array}$ \\
\hline Seg. 4 & $\begin{array}{l}\text { (a) This is a letter about } \\
\text { children in war, (b) so stop } \\
\text { reading and switch your } \\
\text { attention to something more } \\
\text { pleasurable, such as what } \\
\text { you'll have for dinner, or } \\
\text { what's on the television } \\
\text { tonight. }\end{array}$ & $\begin{array}{l}\text { Segment 4a is a } \\
\text { SITUATION } \\
\text { (General) } \\
\text { Segment } 4 \mathrm{~b} \text { is an } \\
\text { attention-getter } \\
\text { (Gimmick - } \\
\text { Marked device) } \\
\end{array}$ & $\begin{array}{l}\text { Segment } 4 \mathrm{~b} \text { attracts readers' } \\
\text { attention } \\
\text { (by stimulating readers' curiosity } \\
\text { to read more about this letter) }\end{array}$ \\
\hline Seg. 5 & $\begin{array}{l}\text { Life would be far too } \\
\text { stressful if we couldn't } \\
\text { screen out information that } \\
\text { makes us uncomfortable. } \\
\end{array}$ & $\begin{array}{l}\text { Clause relation } \\
\text { between Segment } \\
5 \text { and } 6\end{array}$ & $\begin{array}{l}\text { Segment } 6 \text { is an example to } \\
\text { illustrate the situation of Segment } \\
5\end{array}$ \\
\hline Seg. 6 & $\begin{array}{l}\text { Like, for example, the fact } \\
\text { that over } 50,000 \text { children } \\
\text { are still suffering from the } \\
\text { effects of war in Kosovo. }\end{array}$ & $\begin{array}{l}\text { NEGATIVE } \\
\text { EVALUATION } \\
\text { OF SITUATION } \\
\text { - PROBLEM } \\
\end{array}$ & $\begin{array}{l}\text { suffering is a lexical signal for } \\
\text { the negative evaluation of the } \\
\text { situation as a problem. }\end{array}$ \\
\hline Seg. 7 & Are you still with me? & \multirow{3}{*}{$\begin{array}{l}\text { Gimmick - } \\
\text { marked device } \\
\text { Attention- } \\
\text { maintaining } \\
\text { device }\end{array}$} & \multirow{3}{*}{$\begin{array}{l}\text { Cohere with Segment 4: attention } \\
\text { getter } \\
\text { Speech act - Conversation } \\
\text { approach is shown between } \\
\text { Segment } 7 \text { and } 8 \text {. } \\
\text { It reinforces the reader to read } \\
\text { through the whole message by } \\
\text { quoting the word of "GOOD". }\end{array}$} \\
\hline Seg. 8 & $\begin{array}{l}\text { Good, because statistically } \\
\text { speaking about } 30 \% \text { of } \\
\text { readers normally would have } \\
\text { stopped by the time they } \\
\text { read that fact. }\end{array}$ & & \\
\hline Seg. 9 & $\begin{array}{l}\text { And if you have made it this } \\
\text { far, you are probably ready } \\
\text { for another one: }\end{array}$ & & \\
\hline
\end{tabular}




\begin{tabular}{|c|c|c|c|}
\hline Seg. 10 & $\begin{array}{l}\text { It's been a year since the } \\
\text { NATO bombings. }\end{array}$ & \multirow{2}{*}{$\begin{array}{l}\text { Clause relation } \\
\text { between Segment } \\
10 \text { and } 11 \\
\text { NEGATIVE } \\
\text { EVALUATION } \\
\text { OF SITUATION } \\
\text { - PROBLEM }\end{array}$} & \multirow{2}{*}{$\begin{array}{l}\text { However is a word showing } \\
\text { the contrast-relation between } \\
\text { situation stated in segments } 9 \\
\text { and } 10 . \\
\text { "life... is even worse" is a lexical } \\
\text { signal for the negative evaluation } \\
\text { of the situation as a problem. }\end{array}$} \\
\hline Seg. 11 & $\begin{array}{l}\text { However, for many children, } \\
\text { life after the war is even } \\
\text { worse than during the } \\
\text { conflict. }\end{array}$ & & \\
\hline Seg. 12 & $\begin{array}{l}\text { Ula, an ethnic Albanian } \\
\text { adolescent in Pristina, will } \\
\text { be reading a letter from her } \\
\text { brother just as you read this } \\
\text { one. }\end{array}$ & $\begin{array}{l}\text { SITUATION } \\
\text { (specific to the } \\
\text { girl) }\end{array}$ & Situation of reading a letter \\
\hline Seg. 13 & $\begin{array}{l}\text { Reading helps her escape } \\
\text { from the confines of her bed. }\end{array}$ & $\begin{array}{l}\text { SOLUTION } \\
\text { (specific and } \\
\text { virtual) }\end{array}$ & $\begin{array}{l}\text { "help", "escape" are lexical } \\
\text { signals for the solution to the } \\
\text { problem. }\end{array}$ \\
\hline
\end{tabular}

Table 4: Illustrated analysis of an appeal letter from UNICEF - data text 1 (from Seg. 1 to 13)

Based on all four full analyses of the data texts, it was found that the moves of Response and Solution need to be described better. Some refinements of those moves are made as follows.

\subsubsection{Problem-Solution Structure: Two meanings of responses}

It is important to solicit the response from readers to take the action of donation to the organization, i.e. to ask for the action of making a donation to the organization. Then, a response to the problem can be made by the organization after receiving the donation from the readers. Thus, the two meanings of 'response' reside either in the donor or the organization. In addition, it should be noted that response is near to the end of the text to remind or solicit response from the donor. The meaning of response for fund-raising texts is then exemplified as follows:

\section{a) an action of donating money from readers}

e.g. Please donate what you can every month. Your regular support helps ensure that our projects get the funding they need. (response to donate)

\section{b) a reply to the problem by the charity organization}

e.g. delivered 60 metric tonnes of medical supplies (as a response) to the victims who were hurt in the war (as a problem)

Similar to the move of response, 'solution' also needs to be refined. The different aspects of solutions are exemplified in the following section. 


\subsubsection{Problem-solution structure: Aspects of solution}

Among consultants on fundraising and communications for nonprofit organizations worldwide, Burnett (1996) and Williams (2013) explain that donors want to see evidence of sensible use of resources, so solutions to the problems in the past should be provided. On the other hand, some solutions are proposed because donors like to know how their gift will be used and what it will achieve. Burnett (1996: 103) clearly points out that there are different aspects of solutions and they are now classified with reference to different parameters: (1) tangibility, (2) time frame and (3) depth of target-achievement.

(1) Tangibility: tangible and virtual solution

Tangibility refers to the help that can be either physical or intangible.

Tangible solution: Solutions are physical products given to the needs, such as food, tonnes of medical supplies, etc.

Text 1:

Seg.

20 A little help from our donors has repaired 380 school buildings this year.

21 That little help has delivered 60 metric tonnes of medical supplies.

Virtual solution: Solutions are intangible, uncountable and abstract.

Seg.

17 She would like to forget about her own misery.

22 The same help has provided counseling to hundreds of child casualties of landmine accidents.

(2) Time frame: proposed and referent solution

Solutions are classified in terms of time sequence: past or future

Proposed solution: Solution is proposed to be made - (future)

Text 1:

Seg.

19 Help from UNICEF means she will be one of hundreds of children to be reunited with their families.

Text 4:

Seg.

22 Like everyone else, Zhang Xiuhen hopes that a water system can be built so that there will be safe water at the tap.

Reference solution: Solutions are carried out (previous records) to show as an evidence of sensible uses of resources. 
Text 4:

Seg.

14 Oxfam has launched a number of poverty alleviation and development projects...

23 Oxfam has started a training project to help women...

(3) Depth of target-achievement: ultimate and specific Solution

Solutions are classified in terms of depth of target achievement - Ultimate and Specific Solution.

Ultimate solution: Final target to be achieved with reference to the aim of writing the fund-raising text

Specific solution: Specific solutions are those required to be achieved for arriving at the ultimate solution.

Text 3:

Seg.

19 UNICEF helps the majority to climb out of poverty (Ultimate Solution) by supplying loan. (Specific Solution)

18 Aims to improve the living conditions of poor rural women and their children (Ultimate Solution) by providing social services, such as basic health, education. water and sanitation. (Specific Solutions)

To conclude, 'solution' is important for the fund-raising text because donors want to see evidence of sensible use of resource and that is the reality of solution to the problem. Therefore, tangible and referent solutions are produced. In addition, every donor wants to know how his or her gift will be used and what it will achieve, so a proposed solution is derived. Finally, an ultimate solution should be clearly stated in the text and the ultimate one can only be achieved by getting the specific solution done.

\subsubsection{Generalized structure from analyzing data texts}

Some moves of the 'Problem-Solution Structure' have been refined as above, and this refined model is applied in those four texts. To sum up, as for Research question 1 of this study, the generalized structure from those four texts is summarized as follows:

a) The situation-problem-response-solution-evaluation discourse pattern is found to operate in all moves the writers make. However, there is no fixed pattern of 'Problem-Solution Structure' and there are different combinations of situation-problem-response-solution-evaluation for those four data texts. 
b) Obviously, the first move in the structure of fund-raising texts is situation or problem; situation or problem is generally stated at the very beginning and it clearly states what the main theme is in the fund-raising text.

c) Then, the second move can be response, solution or problem, so there are different combinations and hence, varieties of 'Problem-Solution Structure' are derived with reference to different combination patterns.

d) However, the final move is always response and two meanings of response are presented: (i) response from readers to donate to the charity and (ii) reply to the problem by the charity. Response is always the final move for fund-raising text because it is crucial to remind readers to take the first step to donate for charity, then response from the charity to the problem can be done.

\subsection{Choice of style}

In the fund-raising texts, persuasion of readers to donate is crucial, and how to engage readers is another issue. Thus, involvement devices are used to encourage readers to become engaged and they are persuaded to donate and that is the choice of style. Tannen $(1989,2005)$ states that involvement devices shaped and elaborated in literary discourse are pervasive in conversation because they create interpersonal involvement. The following section is about the involvement devices in those four data texts used with the aim to engage readers to donate.

\subsubsection{Involvement with readers - using 'YOU'}

According to Smith (1996: 113), "you is the word that is used most frequently in the fundraising letters". True or not, it is indeed used very frequently. Tannen $(1989,2005)$ also highlights that the use of the word you is critical as it provides human interest. She (1989: 27) clearly points out that "stories, anecdotes, and common names have some of the same effect - but the most powerful way to engage the reader is by appealing directly to her: use the word you. That is an involvement device which is aimed to make the reader particular, which increases the possibility to solicit response successfully".

\section{Examples:}

Text 1:

Seg.

3 Can you stop reading and think about something else?

4 so stop reading and switch your attention to something more pleasurable, such as what you'll have for dinner...

7 Are you still with me?

25 Yours sincerely 
Text 2:

Seg.

4 Oxfam is glad you can read this letter.

20 What can $\boldsymbol{Y O U}$ do?

32 You'll be helping children get an education, and their families get out of poverty.

Text 3:

Seg.

You can help to alleviate poverty and changes the lives of China's rural poor so....

You will be making a world of difference not only to Zhang Hun's life but also...

Text 4:

Seg.

...you can help 4 women build energy-saving stoves to make their lives easier.

...you can help improve the livelihoods of 3 families.

\subsubsection{Strategic positon of 'YOU' - increasing response}

As can be found from the leaflet samples shown in texts 3 and 4, the use of you is not so frequent as in the letter samples in texts 1 and 2 . This observation seems trivial, since it is generally known that letters are meant to establish a dialogue with a 'you'. Interestingly, the you appears also in the leaflets which do not frame the reader for a dialogue. While the pronoun you appears in various positions in the text-structure, the letters and leaflets show it in those steps where the anticipated success of the reader's donation (i.e. response) is described, e.g. "you can help 4 women to build energy-saving stoves...". It seems that here the text-structure works together with style in some multiple functions. The use of you appears to make the leaflets borrow from the letter format some relational closing (discussed by Gan 1989: quoted in Bhatia 1993: 55) which aims at establishing good 'business relations', and maybe some emotional satisfaction.

Relational Closing is to add involvement with readers at the end of text by using involvement devices. You is an involvement device and the 'relational closing of you' functions to increase response from readers by being a reminder and also adding more involvement with readers in the text. That is the reason why Response stage is always found at the end of the 'Problem-Solution Structure' in fund-raising texts as discussed at the beginning. All examples showing the 'relational closing of you' are listed as follows:

Examples:

Text 1:

Seg.

24 You've come this far, all we ask of you now is to put aside a minute to fill in the donation form and change the life of a child.

25 Yours sincerely (Complimentary close) 
Text 2:

Seg.

26 Thank you for your joining our work AGAINST poverty and FOR education.

32 You'll be helping children get an education, and their families get out of poverty. (the last sentence)

Text 3:

Seg.

27 You will be making a world of difference not only to Zhang Hung's life but also many other children in China with your kind support. (the last sentence)

Text 4:

Seg.

25 ...you can help 4 women having training, small loans for raising silkworms, and the chance to have safe water, right at the tap. (the last sentence)

To conclude, using 'you - involvement device' in a fund-raising text can engage readers and then solicit response from them. In addition, assuming that the writer and the reader have the same or very similar beliefs and values, the fund-raising text sets out to influence conduct in a very specific way - 'Relational Closing'; that is, to get response from the readers to send in a contribution.

\subsubsection{Imperative clause}

Another choice of style is reflected in the use of imperative clauses in the fund-raising texts. Imperative clauses have the force of a request which is not mitigated. Since it is not mitigated, readers may have a strong resistance towards carrying out the imperative and hence some attention is given to the style of how the imperative clause is worded.

We are faced with one of the obvious features of a fund-raising letter, how the imperative clause is worded when the writer comes down to asking for hard cash. We ought to note that there is a strong resistance by the decoder for the writer to overcome, especially where the decoder has strong feelings about carrying out the imperative.

If an imperative clause is not preceded by a reason, then we predict that the next clause(s) will provide the reason. If, however, the reason does precede the imperative clause, then it is linguistically complete, and no longer predicts the reason-to-come. In wording the desired imperative, the writer has the problem of confronting the reader with a direct or immediate demand for hard cash.

(Winter 1992: 147-48) 
With reference to the four data texts of fund-raising in this research, the following parts are about the imperative clauses used in correspondence to the requirement of Reason, and the imperative clause aims to solicit response from readers. Examples are quoted as follows:

Examples:

Text 2:

Seg.

22 Please donate what you can every month.

23 Your regular support helps ensure that our projects get the funding they need. It also reduces administrative costs.

Seg. 22 is an imperative clause and it is followed by Seg. 23, which states the reason for the imperative clause.

Seg.

31 P.S. Please support Oxfam.

32 You'll be helping children get an education, and their families get out of poverty.

Seg. 31 is an imperative clause and it is followed by Seg. 32, which states the reason for the imperative clause.

Examples:

Text 3:

Seg.

26 Please give generously.

27 You will be making a world of difference not only to Zhang Hung's life but also many other children in China with your kind support.

Seg. 26 is an imperative clause and Seg. 27 is the reason for the imperative clause.

As for Research question 2 of this study, it was concluded that using you and imperative clauses are the choices of style, and the impact is aimed at persuading the readers. The persuasion rests on two factors: on the direct address of readers since the imperative includes a you. Even if that you is not overt, it is very much present. The potential resistance to the grammatical form of the imperative is softened by the reason.

\subsection{Practitioners' voices}

During the ethnographic interviews with respective representatives, the interviewees were particularly asked what specific writing approach they adopted 
when writing their fund-raising texts. With respect to (i) text-structure and (ii) the choice of style - involvement with readers, relevant responses quoted from the representatives were listed as accounts (1) to (9): ${ }^{3}$

\subsubsection{Practitioners' voices on the Problem-Solution Structure}

We [Oxfam] don't say we deliberately use the problem-solution structure when writing our fund-raising texts. Instead, we truly want to let the public know the REALITY of the world. We aim to reveal the reality, such as the reality of poverty, the reality of earthquake, the reality of war.

(Oxfam representative)

(2) We [Oxfam] do need the public's response and support. And we know we need to tell all donors where their donations 'go'. So, we make that very specific to donors: with their money, for example, we can build 20 schools; we can support children's education and improve people's livelihood, etc.

(Oxfam representative)

(3) Children are most vulnerable to the unpredictable natural disasters and wars. In our fund-raising letters, we [UNICEF] aim to raise the public's awareness of those disadvantaged children's difficulties. For instance, some children lack access to food and safe drinking water, or some don't have any education. We work to advance the basic rights of every child.

(UNICEF representative)

(4) With donors'support, we [UNICEF] can ease those disadvantaged children's lives through providing them with better health services, education, clean water, and shelters. We work to protect and improve conditions for needy children, helping them to have a bright future.

(UNICEF representative)

(5) We [UNICEF] aim to make the world a place where every child can grow to adulthood in health, peace and dignity.... We want more support from donors, by telling them how their donations will be "well-spent". As such, we would say: with their donations, we can build 10 hospitals, or we can help 50 village children to have education, etc.

(UNICEF representative)

\subsubsection{Practitioners' voices on the choice of style (involvement with readers)}

(6) We [Oxfam] do need responses from our readers of our fund-raising texts. We hope the readers will act to donate, so we provide readers with a return envelope for donation, or an autopay authorization form. And we would say "please support us" or "please donate generously".

(Oxfam representative) 
(7) Well, it's true that we [Oxfam] use the pronoun 'you' many times in our fundraising texts. We hope our fund-raising texts are written in the way of talking to a friend, and we may use a letter format as well.

(Oxfam representative)

(8) Speaking of what choice of writing style we [UNICEF] adopt, we try to have more readers' involvement and their understanding of what we are doing. And we use 'you', such as saying "your generous support can help...", "You will make a world of difference".

(UNICEF representative)

(9) Also, we [UNICEF] may use stories or anecdotes, telling readers what specific and difficult situations those disadvantaged children are facing, such as those without clean drinking water or shelters. By sharing the needy children's stories with readers, we hope our readers will act to donate.

(UNICEF representative)

\subsubsection{Linguists meet practitioners: Analysis from practitioners' voices}

Given what practitioners have expressed (Accounts 1-9) in the ethnographic interviews, the following points were extracted, particularly with respect to the text-structure and choice of style.

a) The interviewees/practitioners responded that they did not deliberately use the 'problem-solution structure' when writing. However, it is found that the practitioners use different 'terms/phrases' which seem to be in line with that structure. Based on Accounts 1 and 3, the practitioner at Oxfam emphasized that they aim to tell the public the reality of the world, and the one at UNICEF pointed out that they promote the basic rights of the needy children. Rather than using the term problem(s) directly, some phrases such as the reality of war and the reality of earthquake quoted in the Oxfam interview clearly point to problems. Some phrases such as lack access to food and safe drinking water quoted in the UNICEF interview reveal the problems some children are facing.

b) As for solutions to problems, both interviewees responded that they aim to tell the donors what, with their support, the organizations can do (cf. Accounts 2, 4 and 5). They responded that, when writing, they use verbs such as build, improve, support, promote, provide, etc., and those verbs appear to reveal 'solutions' to problems stated in their fund-raising texts.

c) Both practitioners in the interviews stressed that they aim to make it specific to donors/readers how their donations are going to be 'well-spent' (cf. Accounts 2 and 5). They make their solutions 'measurable', for example, they can build 20 schools or ten hospitals, or help 50 village children to get education, etc. 
Those quantified tasks can be argued to be in line with the finding of tangible solutions in the textual analysis (cf. also Section 4.1.4).

d) Both practitioners also emphasized the reader involvement (cf. Accounts 6 and 8). The practitioners admitted using the pronoun you, and they also aimed to tell the readers the reasons when urging them to donate (cf. Accounts 7-9). As for Research question 3 of this study, when comparing linguists' views and practitioners' views on text-structure, there is evidence given in this section of practitioners' voices that 'Problem-Solution Structure' is to operate in the texts. Though the practitioners in the ethnographic interviews did not acknowledge using a problem-solution structure, a generalized problem-solution structure is made with reference to the text-structure analyses of the four data texts (cf. Section 4.1.5). In addition, practitioners also emphasized reader involvement as their choice of style in their fund-raising texts. They admitted using the pronoun you and 'imperative clause with reasons to donate' in their writing, and those writing techniques are also found to be suggested by academic professionals. All in all, the above findings of this study appear to reveal that the linguists' views and practitioners' views on the text-structure and the choice of writing style coincide (cf. also Section 6 Limitation below).

\section{Conclusions}

To conclude, fund-raising texts represent a particular type of genre. It includes the sub-genres appeal letter and leaflet which are types of fund-raising texts sent and received by way of direct mail. The similarities and differences between appeal letters and leaflets were established by looking at their text-structure and the choice of style. Regarding the first research question about the schematic structure of the fund-raising texts, the 'Problem-Solution Pattern' is to operate in the fund-raising texts. 'Situation' or 'problem' is always placed at the beginning of the text because it is crucial to let readers know what the main theme is. Then, there are different combinations of the second move including 'response', 'solution' or 'problem'. The final move is always 'response' and two meanings of response are refined for the fund-raising texts: (i) an action of donating money from readers to the organization and (ii) a response to the problem by the organization. In addition, there is a discovery that the move of solution needs to be refined better with reference to different parameters: (i) tangibility: tangible and virtual solution, (ii) time frame: proposed and referent solution and (iii) depth of target-achievement: ultimate and specific solution. Another focus of this study is on the choice of style for the fund-raising texts. As persuasion of readers to donate is crucial, adding involvement devices is to engage readers and make them particular, which increases the possibility to solicit 'response' 
successfully. Involvement devices include using you and imperative clauses. As for the final research question, during the interviews the practitioners did not acknowledge that they use any linguistic model or concept; they emphasized that they need to tell readers about the reality: reality of situation, problem and solution. With reference to the issue of whether 'text-structure tell us the reality' or 'the reality creates the structure', practitioners are not concerned too much with text structure and they are concerned to present the reality. Practically, the reality is reflected on the structure embodiment.

\section{Limitation}

The data collection is limited to two interviews with practitioners from two non-profit making organizations, and also only four samples of fund-raising texts are selected for conducting an analysis. However, this study can be treated as an exploratory one to study how linguists and practitioners inform one another on writing fund-raising texts, and what the schematic structure and choice of style in the fund-raising texts are from a practitioner's perspective.

\section{Acknowledgement}

I would like to express many thanks to the (co)editor and two reviewers of this Journal for their constructive comments on this paper, and also to Dr. Bruche-Schulz for her valuable feedbacks on this paper. This paper has been presented at the $9^{\text {th }}$ Malaysia International Conference on Languages, Literatures, and Cultures (MICOLLAC) in Penang on 17 Aug 2016, and I would express my sincere thanks to the audience at my presentation there, particularly Professor Adam Jaworski (School of English, The University of Hong Kong) for his comments.

\section{References}

Atkinson, P. (2001) Handbook of Ethnography. London: Sage.

Atkinson, P. and Hammersley, M. (2007) Ethnography: Principles in Practice. London: Routledge.

Bazerman, C. (1997) 'Some informal comments on texts mediating fund-raising relationships: Cultural sites of affiliation.' Written Discourse in Philanthropic Fund Raising: Issues of Language and Rhetoric 98 (13), 17-26.

Bhatia, V. K. (1993) Analysing Genre: Language Use in Professional Settings. London: Longman.

Bhatia, V. K. (1998) 'Generic patterns in fundraising discourse.' New Directions for Philanthropic Fundraising 22, 95-110.

Bhatia, V. K. (2004) Worlds of Written Discourse: A Genre-Based View. London and New York: Continuum.

Bhatia, V. K. (2008) 'Genre analysis, ESP and professional practice.' English for Specific Purposes 27 (2), 161-174. 


\section{A Discourse Description of Four Fund-Raising Texts - Linguists Meet \\ Practitioners: An Exploratory Study}

Bhatia, V. K. (2010) 'Interdiscursivity in professional communication.' Discourse and Communication 4 (1), 32-50.

Bryman, A. (2008) Social Research Methods. New York: Oxford University Press.

Burnett, K. (1996) Friends for Life: Relationship Fundraising in Practice. London: The White Lion Press Limited.

Callow, K. and Callow, J. (1992) 'Text as purposive communication.' In: Mann, W. and Thompson, A. (eds) Discourse Description: Diverse Linguistic Analyses of a Fundraising Text. 5-38.

Clarke, S. and Norton, M. (1997) The Complete Fundraising Handbook. London: Directory of Social Change.

Connor, U. and Gladkov, K. (2004). 'Rhetorical appeals in fundraising direct mail letters.' In: Connor, U. and Upton, T. A. (eds) Discourse in the Professions: Perspectives from Corpus Linguistics. Amsterdam: John Benjamins. 257-286.

Grimes, J. (1975) The Thread of Discourse. The Hague: Mouton.

Gunnarson, B.-L. (1997) 'The writing process from a sociolinguistic viewpoint.' Written Communications 16 (2), 139-188.

Hoey, M. (1983) On the Surface of Discourse. London: George Allen and Unwin.

Hoey, M. (1991) Patterns of Lexis in Text. Oxford: Oxford University Press.

Hoey, M (1994) 'Signalling in discourse: A functional analysis of a common discourse pattern in written and spoken English.' In: Coulthard, M. (ed.) Advances in Written Text Analysis. 26-45.

Hoey, M. (2001) Textual Interaction: An Introduction to Written Discourse Analysis. London: Routledge.

Kotler, P. and Armstrong, G. (2014) Principles of Marketing. Boston: Pearson.

Kaplan-Weinger, J. and Ullman, C. (2015) Methods for the Ethnography of Communication: Language in Use in Schools and Communities. New York: Routledge.

Labov, W. (1997) 'Some further steps in narrative analysis.' Journal of Narrative and Life History 7, 395-415.

Mann, W., Mathiessen, C. and Thompson, S. (1992) 'Rhetorical structure theory and text analysis.' In: Mann, W. and Thompson, A. (eds) Discourse Description: Diverse Linguistic Analyses of a Fund-Raising Text. 39-78.

Mann, W. and Thompson, S. (1992) Discourse Description: Diverse Linguistic Analyses of a Fund-Raising Text. Amsterdam: John Benjamins.

O'Reilly, K. (2009) Key Concepts in Ethnography. London: Sage.

Richards, J., Platt, J. and Platt, H. (1998) Longman Dictionary of Language Teaching and Applied Linguistics. Hong Kong: Longman.

Rotzoll, K. B., Haefner, J. E., and Sandage, C. H. (1986) Advertising in Contemporary Society. West Chicago, IL: South-Western Publishing Company.

Smith, G. (1996) Asking Properly: The Art of Creative Metaphor. San Diego: Academic Press.

Spivey, N. N. (1997) The Constructionist Metaphor. San Diego: Academic Press.

Tannen, D. (1989) Talking Voices: Repetition, Dialogue and Imagery in Conversational Discourse. New York: Cambridge University Press.

Tannen, D. (2005) Conversational Style: Analyzing Talk Among Friends. New York: Oxford University Press.

Van Dijk, T. (1993) 'Principles of critical discourse analysis.' Discourse and Society 4, 249-283.

Van Dijk, T. (2001) 'Critical discourse analysis.' In: Tannen, D., Schiffrin, D. and Hamilton, H. (eds) Handbook of Discourse Analysis. 352-371. 
Weinstein, S. (2009) The Complete Guide to Fundraising Management. N.J.: John Wiley $\&$ Sons.

Wharton, C. (2015) Advertising: Critical Approaches. Abingdon, Oxon: Routledge.

Williams, K. A. (2013) Leading the Fundraising Charge - The Role of the Non-Profit Executive. NJ: John Wiley and Sons, Inc.

Winter, E. (1976) Fundamentals of Information Structure: A Pilot Manual for Further Development According to Student Need. The Hatfield Polytechnic.

Winter, E. (1992) 'The notion of unspecific versus specific as one way of analyzing the information of a fund-raising letter.' In: Mann, W. and Thompson, A. (eds) Discourse Description: Diverse Linguistic Analyses of a Fund-Raising Text. 131-170.

(Endnotes)

i Also cf. the journal New Directions for Philanthropic Fundraising for more research studies.

ii As for ethnographic interviews, O'Reilly (2009: 22) points out that "sometimes it is difficult to decide who to talk to, ask questions of, or interview... it is important to try to include in fieldwork conversations those who are in some way representative of the group."

iii The two ethnographic interviews were conducted in Cantonese, and those interviewees' accounts (1) to (9) were translated into English by the author of this paper. Given that the author's everyday languages are Cantonese and English, this free translation is believed to reproduce the original meanings.

Patrick Chi-Wai Lee is an Assistant professor at Caritas Institute of Higher Education, Hong Kong. He earned his $\mathrm{PhD}$ in linguistics and English language at the University of Newcastle upon Tyne and his research interests include discourse analysis, sociolinguistics, and second language acquisition in syntax.

\section{Address:}

Dr. Patrick Chi-Wai Lee, Ph.D., School of Humanities and Languages, Caritas Institute of Higher Education, 18 Chui Ling Road, Tseung Kwan O, Hong Kong. China. [e-mail: cwlee@cihe.edu.hk/patrickchiwailee@gmail.com] 